\title{
The correlation between helicobacter pylori Infection, hyperemesis gravidarum, and anemia among pregnant females ... Effect of treatment
}

\section{Original Article}

Emad Salah and Mahmoud Soliman

Department of Obstetrics and Gynecology Faculty of Medicine, Cairo University, Cairo, Egypt

\begin{abstract}
Objective: The aim of this study was to detect the relationship between Helicobacter pylori (H.pylori) infection and pregnancy related disorders: anemia and hyperemesis gravidarum.

Study Design: It was a prospective study. Randomized control study.

Patients and methods: In our study pregnant women between 6-12 weeks of gestation were divided into 3 groups: control group of 144 patients, hyperemesis gravidarum group of 88 patients, anemia group of 128 patients. Seropositivity for H.pylori was studied in each group. H.pylori positive patients in anemia group were divided into two groups and asked to return in second trimester and one group of them recieved treatment of anemia alone, while the other one recieved treatment of anemia and H.pylori treatment and the change in hemoglobin $(\mathrm{Hb})$ levels was detected in both groups

Results: The percentage of H.pylori seropositive patients in the control group was $45.8 \%$, in hyperemesis group $86.4 \%$ while in the anemia group was $84.4 \%$ ( $p$ value $<0.001$ ). The change in $\mathrm{Hb}$ in the group which was given treatment of anemia alone was $0.936 \pm 0.325$ while it was $1.438 \pm 0.354$ in the group which was given treatment for anemia plus treatment to eradicate H.pylori $(P$ value $<0.001)$.

Conclusions: Our study showed strong association between H.pylori infection and hyperemesis gravidarum and we suggested screening of H.pylori in cases with hyperemesis especially in severe cases. And we founded great benefit in eradication of H.pylori infection with treatment of anemia in pregnant women.
\end{abstract}

Key Words: anemia, helicobacter pylori, hyperemesis gravidarum.

Received: 12 April 2017, Accepted: 30 April 2017

Corresponding Author: Emad Salah, Department of Obstetrics and Gynecology Faculty of Medicine, Cairo University, Cairo, Egypt, Tel.: 01005191412, E-mail: Emadsalah148@gmail.com

ISSN: 2090-7265, August 2017, Vol. 7, No. 3

\section{INTRODUCTION}

Half of world population is infected with Helicobacter pylori (H.pylori). Infection is more frequent in developing countries .usually acquired in childhood causing symptomless chronic infection, but few cases may experience some diseases e.g peptic ulcers or GIT carcinoma in adulthood ${ }^{[1,2]}$.

Nearly half of pregnant women experienced nausea and vomiting in the first trimester and usually these symptoms are mild and releaved by modifying diet and giving vitamins and fluid ${ }^{[3]}$. Only $1 \%$ of pregnant women are affected by the severe form of nausea and vomiting known as hyperemesis gravidarum resulting in weight loss, electrolyte imbalance and dehydration. The exact aetiology of hyperemesis still unknown ${ }^{[4]}$.

Strong association between H.pylori infection in pregnant women and development of hyperemesis gravidarum. This association is demonstrated by many case control study e.g Golberg et al $2007^{[5]}$.

Iron deficiency anemia is the most common nutritional disorder affecting billion of people around the world and cause many systemic disorders e.g immune, reproductive and cognitive disorders ${ }^{[6]} .4,4 \mathrm{mg}$ of iron/day is needed in normal singleton pregnancy and supplementation of iron is needed when diet is not enough to meet iron demands per day ${ }^{[7]}$.

Many recent studies suggested that there is positive relationship between H.pylori infection and iron deficiency anemia , mechanisms that have been suggested to clear this relationship include change in the $\mathrm{PH}$ of stomach by H.plori infection which lead to decrease $\mathrm{PH}$, decrease vitamin $\mathrm{C}$ in the stomach and sequestration of iron and ferritin by the $\operatorname{organism}^{[8]}$. 
In this study we studied the incidence of H.plori infection in pregnant women with hyperemesis and anemia, the relation between H.pylori infection and severity of hyperemesis, and the effect of eradication of H.pylori infection on treatment of anemia in pregnant women.

\section{PATIENTS AND METHODS}

This study was conducted in Kasr EL Ainy hospital from March 2016 to December 2016. Our study was prospective randomized control study containing 360 pregnant women between 18 and 35 years with gestational age between 6 and 12 weeks divided into 3 groups (group A): control group containing 144 normal pregnant women. (Group B): 88 pregnant women with hyper emesis gravidarum. Hyperemesis gravidarum defined as vomiting 3 times or more per day with deterioration in the general condition in the form of dehydration, loss of weight more than $3 \mathrm{~kg}$ or 5 percent of total body weight and starvation ketosis proved by positive ketone in urine at least once. (Group C): 128 pregnant women with iron deficiency anemia (IDA). IDA defined as hemoglobin below $11 \mathrm{gm} /$ dl with MCV below $80 \mathrm{fl}$, with one of the following serum ferritin below or equal $25 \mathrm{ng} / \mathrm{ml}$ or transferrin saturation below 20 .

All patients were subjected to full history and examination and H.pylori was investigated by detection of immunoglobulin $G$ in the serum using one step H.pylori serum/plasma test device its qualitative test using membrane-based immunoassay for detection of Ig G of H.pylori with sensitivity $95.9 \%$ and spesifity $86.9 \%$ (Rapid diagnostic H.pylori test Kits, Clungene, Hangzhou Clongene Biotech CO, Zehjiang, China ). 5 millimeters of venous blood was collected and centrifuged for 10 minutes and serum was used to detect the precence of H.pylori immunoglobulin $G$ in the serum sample. Although it's simple and cheap test but it cannot differentiate between old and recent infection.

Group A, the control group was subjected to history taking about number of vomiting per day and complete blood picture (CBC). Group B, the study group with hyperemesis gravidarum was subjected to history taking about the number of vomiting, determination of body weight, examination for signs of dehydration and urine examination for ketone bodies. Any patient with multiple pregnancy, GIT disorder, thyroid disease, intracranial disorders, and recent history of antibiotic intake or psychological disorder was excluded from this group. Group C, the study group with IDA was subjected to investigation in the form of $\mathrm{CBC}$, TIBS, and serum iron and serum ferritin. Any patient with GIT disorder like ulcers of stomach, intestine or bleeding per rectum, renal disease, hyperemesis gravidarum, parasitic infection or recent history of antibiotic intake was excluded from this group. Patients of group C proved to have H.pylori infection asked to come in the second trimester to correct anemia and were divided into two groups. The first group (Group 1) was treated for IDA alone (Pravotin ${ }^{\circledR}$, Lactoferrin-100 mg, Granules for oral suspension, twice daily for one month), without eradication of H.pylori. The second group (Group 2) was treated with iron to correct anemia (Pravotin ${ }^{\circledR}$, Lactoferrin $-100 \mathrm{mg}$, Granules for oral suspension, twice daily for one month) and treatment of H.pylori in the form of $1 \mathrm{gm}$ ampicillin, $500 \mathrm{mg}$ metronidazole and $20 \mathrm{mg}$ omeprazole, all oral treatment twice daily for two weeks.

After one month complete blood picture for both groups was done and the difference between responses of both groups was statistically studied.

\section{STATISTICAL METHODS}

The data were coded, entered and processed on an IBM-PC compatible computer using statistical package for social sciences (SPSS) version 17. A $P$-value of $<0.05$ was considered significant.

Unpaired Student's t-test was used to assess the statistical significance of the difference between two population means and medians in a study involving independent samples.

\section{RESULTS}

360 patients enrolled in this study. The mean age among the control group was $25.01 \pm 5.38$, among the anemia group $25.56 \pm 5.08$ while that of hyperemesis group $25.39 \pm 5.63$ so no statistical difference between groups in relation to age (P-value 0.689$)$. No statistical difference between groups in relation to gravidity. The control group $1.63 \pm 0.83$, the anemia group $1.61 \pm 0.75$ while the hyperemesis group $1.59 \pm 0.66$ (P-value 0.946 ) (Table 1).

The percentage of H.pylori seropositive patients in the control group was $45.8 \%$ while in hyperemesis group $86.4 \%(P$-value $<0.001)($ Table 1$)$.

Regarding the number of vomiting per day, it was noticed that percentage of H.pylori increased with increased number of vomiting, with no vomiting percentage was $42.5 \%$, vomiting NED (not every day) percentage was $58.3 \%$, 12- times per day was $66.6 \%, 3$ times per day was $68.8 \%, 4$ times per day $94.7 \%$ while more than 4 times per day it was $100 \%$ ( $P$-value 0.001$)$ (Table 2). 
Table 1: Descriptive Data of the three groups

\begin{tabular}{|c|c|c|c|c|}
\hline & Control & Anemia & Hyperemesis & $P$-value \\
\hline age & $25.01 \pm 5.38$ & $25.56 \pm 5.08$ & $25.39 \pm 5.63$ & 0.689 \\
\hline gravidity & $1.63 \pm 0.83$ & $1.61 \pm 0.75$ & $1.59 \pm 0.66$ & 0.946 \\
\hline H. pylori \% & $45.8 \%$ & $84.4 \%$ & $86.4 \%$ & $<0.001$ \\
\hline
\end{tabular}

Table 2: Number of vomiting in relation to H. Pylori, seronegativity and seropositivity

\begin{tabular}{lccc}
\hline & H.Pylori $-\mathrm{ve}$ & H.Pylori $+\mathrm{ve}$ & p.value \\
\hline No Vomiting & $57.5 \%$ & $42.5 \%$ & 0.001 \\
NED & $41.7 \%$ & $58.3 \%$ \\
$1-2$ & $33.4 \%$ & $66.6 \%$ \\
3 & $31.3 \%$ & $68.8 \%$ \\
4 & $5.3 \%$ & $94.7 \%$ \\
$>4$ & $0.0 \%$ & $100.0 \%$ & \\
\hline
\end{tabular}

Table 3: Mean $\mathrm{Hb}$ in both control and anemia groups.

\begin{tabular}{lccc}
\hline & Control & Anemia & P-value \\
\hline H.Pylori \% & $45.8 \%$ & $84.4 \%$ & $<0.001$ \\
Hb mean & $11.9 \pm 0.623$ & $9.7 \pm 0.571$ & $<0.001$ \\
\hline
\end{tabular}

Table 4: Effect of different treatment on $\mathrm{Hb}$ in H.pylori seropositive pregnant women.

\begin{tabular}{|c|c|c|c|}
\hline & Treatment of Anemia & Treatment of Anemia + H.Pylori & P.value \\
\hline Mean $\mathrm{Hb}$ & $9.64 \pm 0.588$ & $9.66 \pm 0.579$ & 0.891 \\
\hline $\mathrm{Hb}$ - Post ttt & $10.51 \pm 0.665$ & $11.05 \pm 0.373$ & $<0.001$ \\
\hline Change in $\mathrm{Hb}$ & $0.94 \pm 0.325$ & $1.44 \pm 0.354$ & $<0.001$ \\
\hline$\%$ reach normal $\mathrm{Hb}(11 \mathrm{~g} / \mathrm{dl})$ & $54.5 \%$ & $71.4 \%$ & 0.105 \\
\hline
\end{tabular}




\section{DISCUSSION}

The prevalence of H.pylori varies significantly between countries according to socioeconomic standard, geographical distribution and method of its detection being more in developing countries e.g in Egypt 80\% while in European countries $20-30 \%{ }^{[9]}$.

It has been noticed that poor reproductive outcome is linked to pregnant women with moderate to severe anemia ${ }^{[10]}$. Pregnant women infected with H.pylori found to have low $\mathrm{Hb}$ level from the start of pregnancy ${ }^{[1]]}$.

Nausea and vomiting is the most common disorder affecting pregnancy the majority of cases are mild not affecting the patient general condition but only in $0.5 \%$ to $1.5 \%$ of pregnancy the condition is severe and known hyperemesis gravidarum. The etiology of such condition not definitely known most of author believed it's linked to high levels of Human Chorionic Gonadotropin proved by increased incidence of hyperemesis gravidarum in multiple pregnancy and molar pregnancy and the improvement occur in such cases when pregnancy is terminated. Other theories link this disorder to high levels of estrogen in pregnancy which lead to accumulation of fluid and change in body $\mathrm{PH}$. This change of body $\mathrm{PH}$ and intestinal $\mathrm{PH}$ will lead to activation of subclinical infection of H.pylori ${ }^{[12]}$.

Our study took place in kasr El Aini in 360 patients divided into 3 groups first group is control group of 144 medically free patients second group is 88 patients with hyperemesis gravidarum and the third group is 128 patients with iron deficiency anemia. The aim of the study was to compare H.pylori seropositivity among three groups, study the relation between severity of symptoms of hyperemesis - referred to by the number of vomitingwith seropositivity of H.pylori and study the effect of adding treatment of H.pylori in the outcome of treatment of iron deficiency anemia.

In our study, it showed no statistical difference in the age group between three groups the control group $25.01 \pm 5.38$, the anemia group $25.56 \pm 5.08$ while that of hyperemesis group was $25.39 \pm 5.63$. Mona $\mathrm{m}$ et al., 2014 founded no statistical difference in the age between control 26.084.88 \pm and hyperemesis group $26.48 \pm 4.97^{[12]}$.

But other studies founded that patients with frequent vomiting and positive H.pylori was older than those who are negative e.g Shirin et al., 2004[13].

Ehab H and Ghada M 2014 founded no statistical difference in age among patients with anemia if they are seropoisitive for H.pylori or not ${ }^{[8]}$.

We founded that the incidence of H.pylori was more in hyperemesis gravidarum group. The control group was $45.8 \%$ while in hyperemesis group $86.4 \%$. Mona M et al., 2014 founded that the percentage of seropositive H.pylori cases in the hyperemesis group was $92 \%$ while in the control group 54\% ${ }^{[12]}$. Melih et al., 2011 reached the same conclusion in their study in Kahramanmaras Sutu Imam University in Turkey with $80 \%$ seropositive cases in hyperemesis group and $35 \%$ in the control group ${ }^{[14]}$.

In the other hand Boltin et al., 2014 showed no statistical difference in the seropositivity of H.pylori between hyperemesis group $75 \%$ and control group $60.4 \%$ $P$ value $0.30^{[15]}$

In our study we founded increase in the percentage of H.pylori with increase the number of vomiting (Table 2) that related the seropositivity of H.pylori to the severity of the symptoms. Shirin et al., 2004 founded high percentage of seropositive H.pylori in cases with mild vomiting but no difference in moderate and severe cases ${ }^{[13]}$. In the other hand Mona M et al., 2014 founded high percentage among cases with severe vomiting as all cases with vomiting more than 4 times was seropositive for H.pylori ${ }^{[12]}$.

The percentage of H.pylori in anemia group was $84.4 \%$ while in the control group $45.8 \%$. Weyerman et al., 2005 studied the $\mathrm{Hb}$ level in pregnant women and founded low $\mathrm{Hb}$ level from the start of pregnancy $(-0.25 \mathrm{~g} / \mathrm{dl}$; $95 \% \mathrm{CI}$ : $-0.49-0.003)$ and more decrease in levels of $\mathrm{Hb}$ in the course of pregnancy $(-0.14 \mathrm{~g} / \mathrm{dl} ; 95 \% \mathrm{CI}:-0.38-0.10)^{[11]}$.

Eradication of H.pylori with treatment of iron deficiency anemia gave better response than treating anemia alone. We founded that with treatment of anemia alone (54.5\%) of patients reached normal $\mathrm{Hb}$ values and mean $\mathrm{Hb}$ after treatment was $10.509 \pm 0.665$, the change in HB was $0.936 \pm 0.325$. But with addition of H.pylori treatment $(71.4 \%)$ of patients reached normal values and mean $\mathrm{Hb}$ after treatment was $11.048 \pm 0.373$, the change in $\mathrm{Hb}$ was $1.438 \pm 0.354$ Ehab H and Ghada M, 2014 founded better response in treatment of anemia in H.pylori seropositive patients after addition of treatment for eradication of $\mathrm{H}$.pylori. The range of $\mathrm{Hb}$ before eradication of H.pylori was $8.4 \pm 0.34 \mathrm{gm} / \mathrm{dl}$, the change in Hb level was $0.4 \mathrm{gm} /$ $\mathrm{dl}$, but with addition of treatment of H.pylori the range of $\mathrm{Hb}$ reach $10.1 \pm .04$ and the change of $\mathrm{Hb}$ was $1.7 \mathrm{gm} /$ dl. ${ }^{[8]}$. Also Chen and Lue, 2007 reached the same result although the study was in non-pregnant females ${ }^{[16]}$.

\section{CONCLUSION}

Our study showed strong association between H.pylori infection and hyperemesis gravidarum and we suggest screening of H.pylori in cases with hyperemesis especially severe cases. And we founded great benefit in eradication of H.pylori infection with treatment of anemia in pregnant women. 


\section{CONFLICT OF INTEREST}

There are no conflicts of interest.

\section{REFERENCES}

1. Malaty HM. Epidemiology of helicobacter pylori infection. Best pract Res Clin Gastroenterol 2007; 21: 205- 214.

2. Suerbaum S, Michetti P. Helicobacter pylori infection. N Englj Med 2002; 347:1175- 1168

3. Broussard CN, Richter JE. Nausea and vomiting of pregnancy. Gastroenterol Clin North Am 1998; 27:12351-

4. Verberg MF, Gillott DJ, AL-Fardan N, Grudzinskas JG. Hyperemesis gravidarum, aliterature review. Hum Reprod Update 2005; 11:527 -39.

5. Golberg D, Szilagyi A, Graves L. Hyperemesis gravidarum and helicobacter pylori infection : a systemic review. Obstet Gynecol 2007; 110:695 -703.

6. Cardenas VM, Mulla ZD, Ortiz M, Graham DY. Iron deficiency and Helicobacter pylori infection in the united states . Am J Epidemiol 2006; 163:127 -134.

7. Milman N, Bergholt T, byg KE, Eriksen L, Graudal N. Iron status and iron balance during pregnancy. A critical reappraisal of iron supplementation. Acta Obestet Gynecol Scand 1999; 78: 749 -757.

8. Ehab H, Ghada M. Helicobacter pylori and anemia with pregnancy. Arch gynecol obestet 2014; 289:1197 -1202.

9. Bassilly S, frenck RW, Mohareb EW, Wierzba T, Savarino S, Hall E, KotkatA, Naficy A, Hyams
$\mathrm{KC}$, Clemens j. seroprevelance of H.pylori among egyptiant newborns and their mothers: preliminary report. Am J Trop Med Hyg 1991: 61;37 -40.

10. Farrag TH, Stoltzfus RJ, Khalfan SS, Tielsch JM. H.pylori infection is associated with severe anemia of pregnancy in pemba island, Zanzibar. AM J Trop Med Hyg 2007;76(3):541- 548.

11. Weyermann M, Rothenbacher D, Gayer L, Bode G, Alder G, Grab D, Flock F, Brenner H. Role of H.pylori infection in iron deficiency during pregnancy. Am J obetet Gynecol 2005: 192;548 -553

12. Mona M, Hisham K, Arwa H. H.Pylori seropositivity in patients with hyperemesis gravidarum. The American journal of the Medical science 2014: 347; 101 -105.

13. Shirin H, Sadan O,Shevah O. Positive serology for H.pylori and vomiting in pregnancy. Arch Gynecol Obestet 2004: 270;10- 14.

14. Melih A, Ibrahim E, Ayhan C, Pinar C. Seriologic and stool antigen assay of H.pylori infection in hyperemesis: which test is useful during early pregnancy?. Taiwanese journal of obstetrics and gynecology 2011:50; $37-41$.

15. Boltin D, Tsachi T, Sami E, Asher S, Yaron N, Hussein S, Ram D. H.pylori infection among arab Israeli women with hyperemesis gravidarum-a prospective controlled study. International Journal of infectious disease 2014:29:292 -295.

16. Chen LH, Luo HS. Effect of H.pylori therapy on erythrocytic and iron parameter in iron deficiency anemia patients with H.pylori positive chronic gastritis. World J Gastroenterol 2007: 13(40); $5380-5383$. 